\title{
Pre-conceptual Development and characterization of an extruded graphite composite fuel for the TREAT Reactor
}

The INL is a

U.S. Department of Energy

National Laboratory

operated by

Battelle Energy Alliance

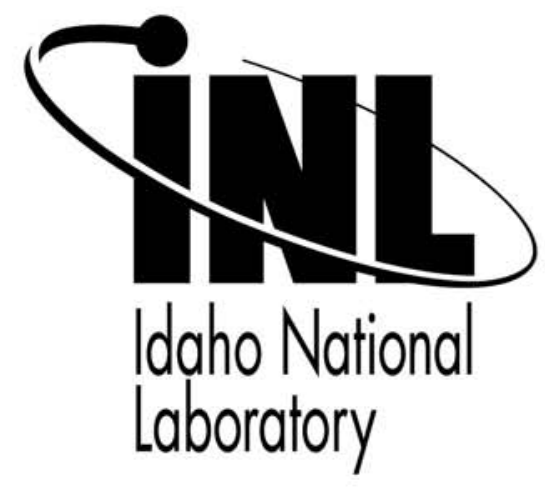

\section{TMS 2015 - Structural Materials Division, Corrosion and Environmental Effects Committee and Nuclear Materials Committee}

Erik Luther, Isabella van Rooyen, ChingFong Chen, David Dombrowski, Rafael Leckie, Pallas Papin, Andrew Nelson

\section{March 2015}

This is a preprint of a paper intended for publication in a journal or proceedings. Since changes may be made before publication, this preprint should not be cited or reproduced without permission of the author. This document was prepared as an account of work sponsored by an agency of the United States Government. Neither the United States Government nor any agency thereof, or any of their employees, makes any warranty, expressed or implied, or assumes any legal liability or responsibility for any third party's use, or the results of such use, of any information, apparatus, product or process disclosed in this report, or represents that its use by such third party would not infringe privately owned rights. The views expressed in this paper are not necessarily those of the United States Government or the sponsoring agency. 


\title{
PRE-CONCEPTUAL DEVELOPMENT AND CHARACTERIZATION OF AN EXTRUDED GRAPHITE COMPOSITE FUEL FOR THE TREAT REACTOR
}

\author{
Erik Luther ${ }^{1}$, Isabella van Rooyen ${ }^{2}$, Ching-Fong Chen ${ }^{1}$, David Dombrowski ${ }^{1}$, Rafael Leckie ${ }^{1}$, \\ Pallas Papin ${ }^{1}$ and Andrew Nelson ${ }^{1}$ \\ ${ }^{1}$ Los Alamos National Laboratory \\ P.O. Box 1663, Los Alamos, NM 87545 \\ ${ }^{2}$ Idaho National Laboratory \\ 2525N Fremont Ave, Idaho Falls, ID 83415 \\ TREAT, nuclear fuel, graphite matrix, $\mathrm{UO}_{2}$
}

\begin{abstract}
To explore fuel systems that are more robust under accident scenarios, the DOE-NE has identified the need to resume transient testing. The Transient Reactor Test (TREAT) facility has been identified as the preferred option for the resumption of transient testing of nuclear fuel in the United States. In parallel, NNSA's Global Threat Reduction Initiative Convert program is exploring options to replace the existing highly enriched uranium core with low enriched uranium (LEU) core. To construct a new LEU core, fabrication processes similar to those used for the original core must be identified and developed. Initially, graphite matrix fuel blocks were either uniaxially pressed or extruded following historic routes; however, the project expanded to explore methods to increase the graphite content of the fuel blocks and modern resins. Materials properties relevant to fuel performance including density and thermal diffusivity were measured. The relationship between process defects and materials properties will be discussed.
\end{abstract}

LA-UR-14-27588

\section{INTRODUCTION}

The Transient Reactor Test Facility (TREAT) reactor located at Idaho National Laboratory (INL) first achieved criticality in 1959. Between 1959 and 1994, TREAT was used to simulate conditions during various types of nuclear excursions including meltdown, thermal interaction between overheated fuel and coolant, and the transient behavior of ceramic fuel at high temperature. The data provided by these tests was used to predict the consequences of accident scenarios and the safety margin for fuel designs.

The U.S. Department of Energy (DOE) approved the resumption of transient testing at the TREAT facility in February 2014. In parallel the National Nuclear Security Administration's Global Threat Reduction Initiative Convert Program is evaluating conversion of TREAT from its existing highly enriched uranium (HEU) core to a new core containing low enriched uranium (LEU). As part of this evaluation, studies were conducted to explore methods to fabricate the dispersion fuel used for the core.

The original HEU core was fabricated as a lifetime core for the reactor; however, in the 1970s, an "upgrade core" was fabricated to increase the capabilities of the reactor.

The original TREAT reactor core is approximately six foot square by four foot high fueled by a dilute dispersion of highly enriched $\mathrm{U}_{3} \mathrm{O}_{8}$ particles in a graphite matrix. The core consists of an array of Zircaloy-3 clad fuel assemblies that are four inch by four inch by eight feet. The assemblies are loaded with four by four by eight inch fuel blocks containing graphite, carbon, and coal tar pitch resin pressed to 
shape.[1] The core fabrication was a joint development effort by Argonne National Laboratory and Great Lakes Carbon.

The TREAT upgrade reactor core was intended to replace the central $11 \times 11$ zone of the full $19 \times 19$ core of fuel element assemblies.[2] The replacement fuel assemblies have the same external geometry as the originals; however, several changes were made. The portion of the assembly containing fuel meat was increased from four to five feet, the fuel particles were changed from $\mathrm{U}_{3} \mathrm{O}_{8}$ to $\mathrm{UO}_{2}$, and the cladding was changed to Inconel. The internal geometry of the fuel was changed from a single block to a 4 x 4 array of square ( 0.94 in on a side) cross section fuel elements. The carbon to uranium ratio was also increased and varied from 700 to $10,000\left(0.225\right.$ to $3.21 \mathrm{wt} \%$ of $\left.\mathrm{UO}_{2}\right)$ depending on the zone in which the fuel element was located. The $\mathrm{C} / \mathrm{U}$ ratio did not vary in the axial dimension. These fuel blocks were fabricated by an extrusion process based on the Rover space reactor fuel element development program performed at Los Alamos Scientific Laboratory (now Los Alamos National Laboratory).[3]

As part of the fuel fabrication studies, LANL was tasked to recover the methods used to fabricate the extruded fuel and produce samples of fuel made by a uniaxial pressing process for characterization.[4,5] In order to achieve optimal neutronics performance, it was desirable to maximize the graphite content of the final composition.[6]

\section{EXPERIMENTAL}

The fabrication of uniaxially pressed fuel blocks consisted of these steps: 1) raw material weighing, 2) mixing, 3) air cooling, 4) pulverizing, 5) preheating, 6) pressing and 7) heat treatment. The fabrication of extruded fuel elements consisted of these steps: 1) raw material weighing and blending, 2) extrusion, 3) binder burnout, and 4) heat treatment. Details on the processes and compositions were found in the literature. [1,2,7]

The raw materials originally used for the matrix of the fuel elements consisted of graphite flour (grade S97 from Airco-Speer Carbon Company) and carbon black (Thermax). For the pressed blocks, coal tar pitch from Kopper Corporation was used for the binder. For the extruded fuel, Varcum resin, a partially polymerized furfuryl alcohol was used. The source of the original $\mathrm{U}_{3} \mathrm{O}_{8}$ for the pressed blocks was not discovered; however, $\mathrm{UO}_{2}$ used for the extrusions was synthesized at LANL. With the exception of the coal tar pitch, these materials are no longer available; however, suitable replacements were identified, procured and characterized to compare with the original materials. Nevertheless, for these experiments, legacy materials were located and used except for $\mathrm{U}_{3} \mathrm{O}_{8}$ and Varcum resin. $\mathrm{U}_{3} \mathrm{O}_{8}$ powder was supplied by Cameco. A Varcum-type resin was prepared from furfuryl alcohol for each experiment.

\section{$\underline{\text { Uniaxially Pressed Fuel Blocks }}$}

Coal Tar Pitch (CTP) was provided as pellets with a size of about $1 / 2$ " diameter and $3 / 4$ " long. The asreceived CTP was crushed using a tungsten carbide mortar and pestle. The crushed CTP powders were screened through a 37 mesh sieve. The -37 mesh CTP powders were loaded into a one gallon high density polyethylene jar filled with $1 / 2 " \mathrm{Al}_{2} \mathrm{O}_{3}$ grinding media and milled at $100 \mathrm{rpm}$ for about 6 hours. The milled CTP powders were then screened through a 175 mesh sieve, which was used as the starting binder.

Table 1 lists the formulation reported by Argon National Laboratory. The formulation appears to be in parts and is somewhat unclear in how it was batched. The formula was converted to weight percent as seen in the second column. $\mathrm{U}_{3} \mathrm{O}_{8}$ was weighed and poured into a polyethylene container loaded with high purity $\mathrm{Al}_{2} \mathrm{O}_{3}$ grinding media and milled for about 10 minutes at $100 \mathrm{rpm}$. CTP as prepared above was weighed and poured into the container to mix with $\mathrm{UO}_{2}$ for about 10 minutes. Carbon black (Thermax) and graphite (Airco) were then weighed and poured into the container and milled for another 6 hours. The milled mixtures were screened through a 37 mesh brass sieve for uniaxial pressing. 
Table 1. Formulation for pressed pellets

\begin{tabular}{|l|l|l|}
\hline & Parts & Wt\% \\
\hline Coal Tar Pitch & 29.4 & 22.5 \\
\hline $\mathrm{U}_{3} \mathrm{O}_{8}$ & 1 & 0.8 \\
\hline Carbon Black & 25 & 19.2 \\
\hline Graphite & 75 & 57.5 \\
\hline Total & 130.4 & 100 \\
\hline
\end{tabular}

For uniaxial pressing, the milled mixture was weighed and poured into a one inch steel die with top and bottom punches to hold the powder. For the initial study, the die with the milled mixture was put into an oven and heated to $90^{\circ} \mathrm{C}^{\mathrm{i}}$ for about 4 hours to remove some volatiles and to let the CTP soften. Four pellets were pressed at 7.5, 10, 15, and $20 \mathrm{ksi}$, respectively. The green densities were determined by measuring the weight divided by the volume, which was measured using a caliper. Figure 1 shows the aspressed green density as a function of the pressing pressures. From this figure, it can be seen that all four pellets have density higher than the minimal required density of $1.72 \mathrm{~g} / \mathrm{cm}^{3}$. The data also shows that 5 ksi is sufficient to achieve a high density and the green density seems to reach a maximum at about 10 ksi. Any pressure increase above $10 \mathrm{ksi}$ seems to decrease the green density, which might be caused by the spring back of the CTP.

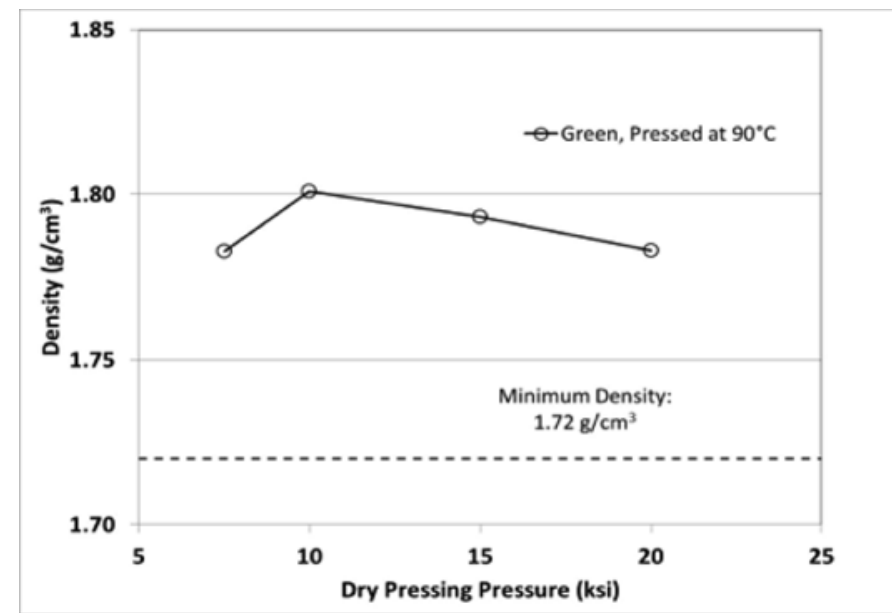

Figure 1. Green density as a function of dry pressing pressure for pellets pressed at $90^{\circ} \mathrm{C}$.

The green pellets are heat treated to $250^{\circ} \mathrm{C}$ in air to remove the volatiles in CTP. The temperature program is a slow heating program with heating from room temperature to $90^{\circ} \mathrm{C}$ in 10 hours, $90^{\circ} \mathrm{C}$ to $110^{\circ} \mathrm{C}$ in 7 hours, and $110^{\circ} \mathrm{C}$ to $250^{\circ} \mathrm{C}$ in 20 hours. A final $925^{\circ} \mathrm{C}$ heat treatment under argon was performed on these pellets to convert the binder to carbon similar to the heat treatment temperature performed by GLC. After the heat treatment, density of the pressed pellets dropped below the specification of $1.72 \mathrm{~g} / \mathrm{cc}$.

Due to the low final density achieved for the pellets, thermal gravimetric analysis (TGA) of the burnout of the CTP was conducted to understand the evolution of volatiles. Based on the information collected, the pressing temperature for the green pellets was increased in order to remove volatiles in the CTP and hopefully increase the final density of the pellets. Figure 2 shows the green density, final density (carbonized density) and shrinkage of pellets as a function of pressing (pre-heat) temperature. As seen in the Figure 2, the green density is essentially constant regardless of pressing temperature; however, the

\footnotetext{
${ }^{\mathrm{i}}$ Temperature measurements throughout this study were made using thermocouples certified to ASTM E230-ANSI MC 96.1 special limits of error.
} 
final density increases dramatically as a function of pressing temperature. This is due to removal of volatiles from the CTP prior to pressing. It appears that a pressing temperature of $160^{\circ} \mathrm{C}$ or above is needed to achieve the maximum density. Figure 2 also shows the thickness expansion and diameter shrinkage as a function of pre-heated temperature. The diametral shrinkage seems change little; however, the thickness expansion reduces significantly as the pre-heat temperature is increased and reaches saturation at about $160^{\circ} \mathrm{C}$.

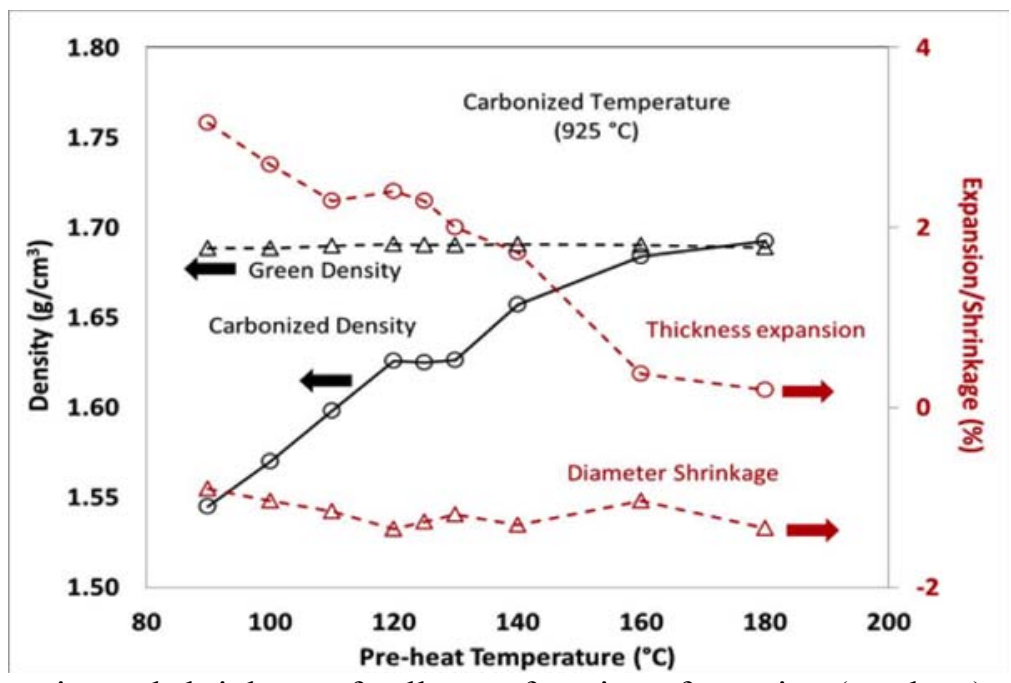

Figure 2. Density and shrinkage of pellets as function of pressing (pre-heat) temperature.

Pellets for morphological characterization were prepared with $\mathrm{U}_{3} \mathrm{O}_{8}$ pressed at $160^{\circ} \mathrm{C}$ and $10 \mathrm{ksi}$ following the procedures described above and heat treated under argon.

The pellets were examined by scanning electron microscopy (SEM) and display a homogeneous crack free microstructure at low magnification, Figure 3. At higher magnification, individual $\mathrm{U}_{3} \mathrm{O}_{8}$ particles can be seen as well as sub-micron pores. Larger smooth areas are either graphite flake or carbonized CTP. Semi-quantitative EDS analysis of the $\mathrm{U}_{3} \mathrm{O}_{8}$ particles indicates an oxygen to uranium ratio of 1.5 to 1.9 as opposed to the expected 2.6 indicating that reduction has occurred. This result is consistent with previous results.[8]

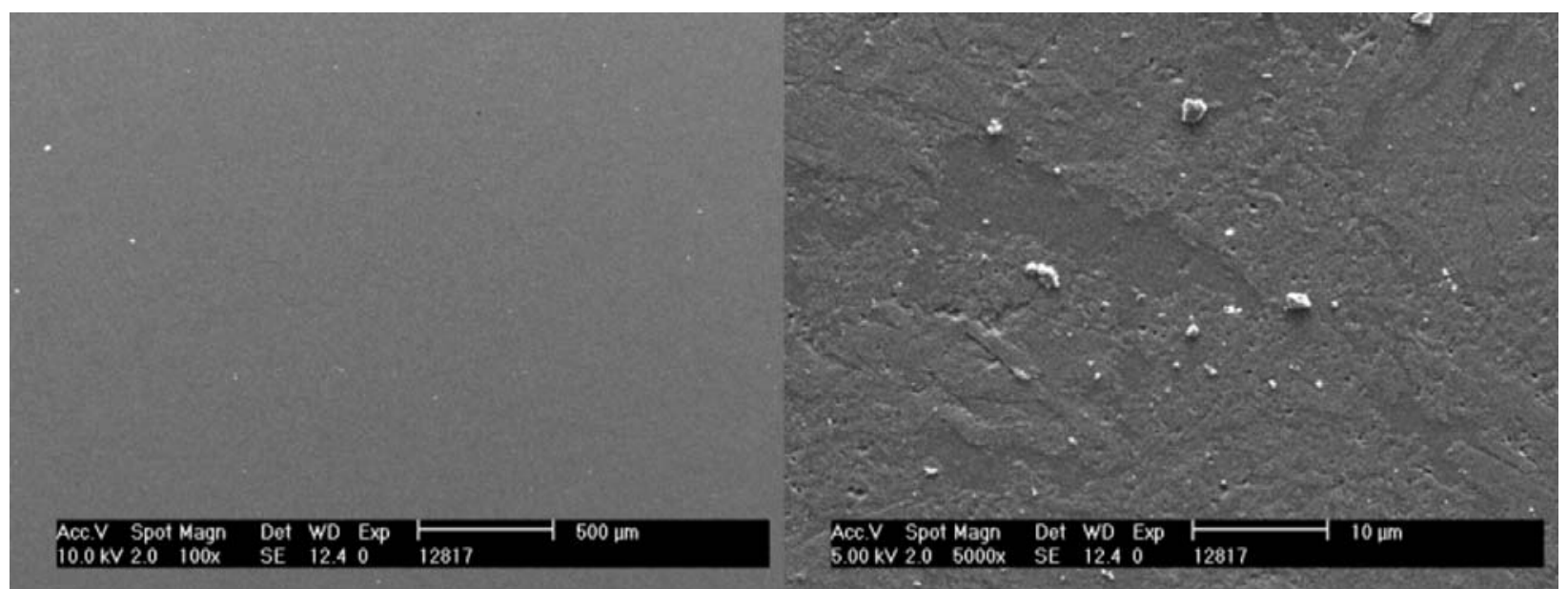

Figure 3. (Left) Low magnification SEM image of pressed pellet showing dispersed $\mathrm{U}_{3} \mathrm{O}_{8}$ (bright spots) and a uniform, crack-free microstructure. (Right) High magnification SEM image of $\mathrm{U}_{3} \mathrm{O}_{8}$ containing pressed pellets showing sub-micron pores and large smooth areas of either graphite flake or carbonized CTP. 


\section{Extruded Fuel Blocks}

Furfuryl alcohol was pre-polymerized with maleic anhydride. $25 \mathrm{~g}$ of maleic anhydride was dissolved in $25 \mathrm{~g}$ of acetone. The dissolved maleic anhydride was added to $500 \mathrm{~g}$ of furfuryl alcohol. A slow, exothermic reaction occurs. After several hours, the solution warms several degrees and changes from straw colored to dark brown. After the initial reaction, the solution is heated to $50^{\circ} \mathrm{C}$ for one hour in a water bath. Four grams of ethyl alcohol are added and the temperature is increased to $60^{\circ} \mathrm{C}$. The viscosity of the solution is monitored every couple of hours to identify an increase in viscosity. Final room temperature viscosity was targeted at 30 to $45 \mathrm{cP}$ as measured with a Brookfield viscometer. No consistent time could be identified for the endpoint of the reaction. This variability is possibly due to a lack of stirring; however, acceptable extrusions could be obtained with viscosities exceeding $100 \mathrm{cP}$ so no process refinement was performed. The partially polymerized resin will continue to cure at room temperature and must be used within approximately one week. Just prior to extrusion, an additional $13 \mathrm{~g}$ of maleic anhydride dissolved in acetone $(50 \% / 50 \%)$ is added to speed the final cure.

Dry powders, graphite, carbon black and uranium oxide were weighed and stirred briefly in a Hobart mixer. Partially polymerized furfuryl alcohol resin (as prepared above) was added to the powders and stirred. The baseline composition mimicked the historical formulation to the greatest extent possible. The amount of resin added was varied slightly as seen in Table II in order to produce an extrudable mass with the desired consistency. The desired consistency is one which is "wet" enough that it will not crack as it is extruded but not too wet which will promote slumping and sticking to the run out plate. After blending, the extrusion mix was then sent through an electric meat grinder equipped with a plate with $1 / 4$ in. holes three times to ensure thorough mixing.

In order to maximize the graphite content of the matrix, carbon black was replaced with graphite. Because the carbon black is significantly finer in particle size $(0.78 \mu \mathrm{m})$ than the graphite $(37.9 \mu \mathrm{m})$, graphite was ball milled for 22 hours. Unfortunately, milling was only able to reduce the median size to $16.0 \mu \mathrm{m}$. With this composition, the calculated graphite content of the sample is increased from $59 \%$ to $72 \%$ graphite. Additional compositions are also seen in Table II. The motivation for these is described below.

Table II: Composition of fuel extrusion mixes

\begin{tabular}{|l|l|l|l|l|}
\hline & \multicolumn{1}{|c|}{$\begin{array}{c}\text { Baseline } \\
\text { (grams) }\end{array}$} & \multicolumn{1}{|c|}{$\begin{array}{c}\text { All Graphite } \\
\text { (grams) }\end{array}$} & \multicolumn{1}{|c|}{$\begin{array}{c}\text { Wood flour } \\
\text { (grams) }\end{array}$} & \multicolumn{1}{c|}{$\begin{array}{c}\text { Epoxy } \\
\text { (grams) }\end{array}$} \\
\hline Uranium oxide & 25.4 & 0 & 12.7 & 0 \\
\hline Graphite & 404.4 & $\begin{array}{l}404.4 \text { unmilled } \\
82.8 \text { milled }\end{array}$ & $\begin{array}{l}404.4 \text { unmilled } \\
82.8 \text { milled }\end{array}$ & $\begin{array}{l}404.4 \text { unmilled } \\
82.8 \text { milled }\end{array}$ \\
\hline Carbon & 82.8 & 0 & 0 & 0 \\
\hline Wood "flour" & 0 & 0 & 56 & 0 \\
\hline Resin & 247 to 267 & 309 to 372 & 471 & 304 \\
\hline
\end{tabular}

The mixture was loaded into a laboratory scale piston type extruder. The piston was extended until the plunger just entered the cylindrical chamber. The open die orifice was plugged with a rubber stopper and deairing was performed for several minutes before extrusion began. For all of the samples, a square die with an approximately $3 / 4$ " height and width was used. Because of the large cross section desired for the samples, the ideal reduction ratio of 7 to 1 was not realized. In this case the material was reduced only about 2.7 times. Extruded material was pushed onto a graphite run out plate with small holes for compressed air that would "levitate" the extrusions similar to an air hockey table.

Historically, extremely long heat treatment cycles have been used to slowly cure and drive off volatiles in the fuel element extrusions. A typical cycle consisted of a ramp to $525 \mathrm{~K}\left(\sim 250{ }^{\circ} \mathrm{C}\right)$ in 63 to 90 hours in air, a ramp to $1100 \mathrm{~K}\left(\sim 827^{\circ} \mathrm{C}\right)$ in 116 hours in vacuum and a final ramp to $1550 \mathrm{~K}\left(\sim 1277^{\circ} \mathrm{C}\right)$ in 3 hours with a two hour hold under vacuum or inert gas. 
Initially heat treatment cycles mimicked the 63 hour cycle but resulted in severe cracking due to evolution of volatile species. Increasing the heat treatment time to 110 hours reduced but did not eliminate cracking as seen in Figure 4. Adding wood flour to the mixture and heat treating under vacuum provided a pathway for volatiles to escape and eliminated cracking, Figure 5. Unfortunately, this approach also required an increase in the quantity of resin required to produce an extrudable mass as seen in Table II. Since both the resin and wood filler convert to amorphous carbon on heat treatment, this approach was contrary to the goal of maximizing the graphite content of the matrix. Instead, the Varcum type resin was switched to a single component epoxy resin (Von Roll), which resulted in an acceptable extrusion with some minimal porosity, Figure 5.
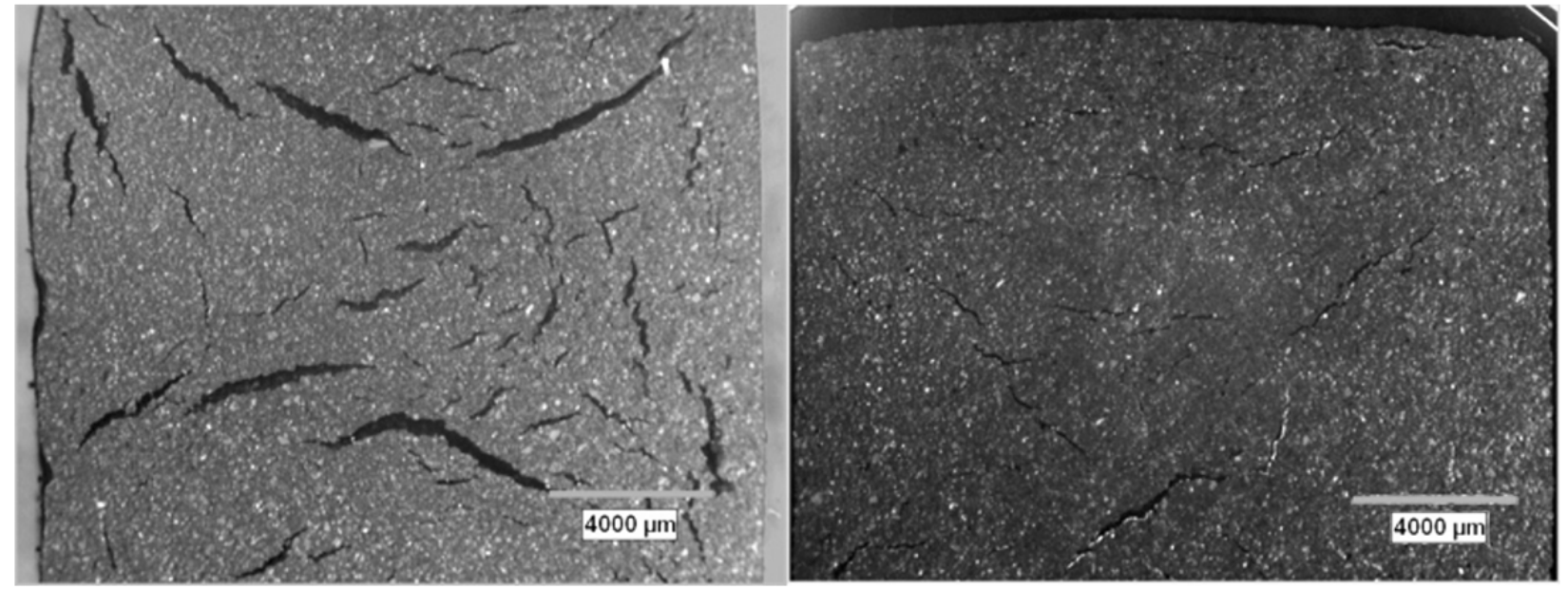

Figure 4. Optical microscopy (5.8x) image of cross sections of graphite extrusion containing $\mathrm{UO}_{2}$ heat treated to $250^{\circ} \mathrm{C}$. The extensively cracked sample on the left had a heat treatment cycle of 63 hours while the heat treatment for the sample on the right was extended to 110 hours, minimizing cracking.
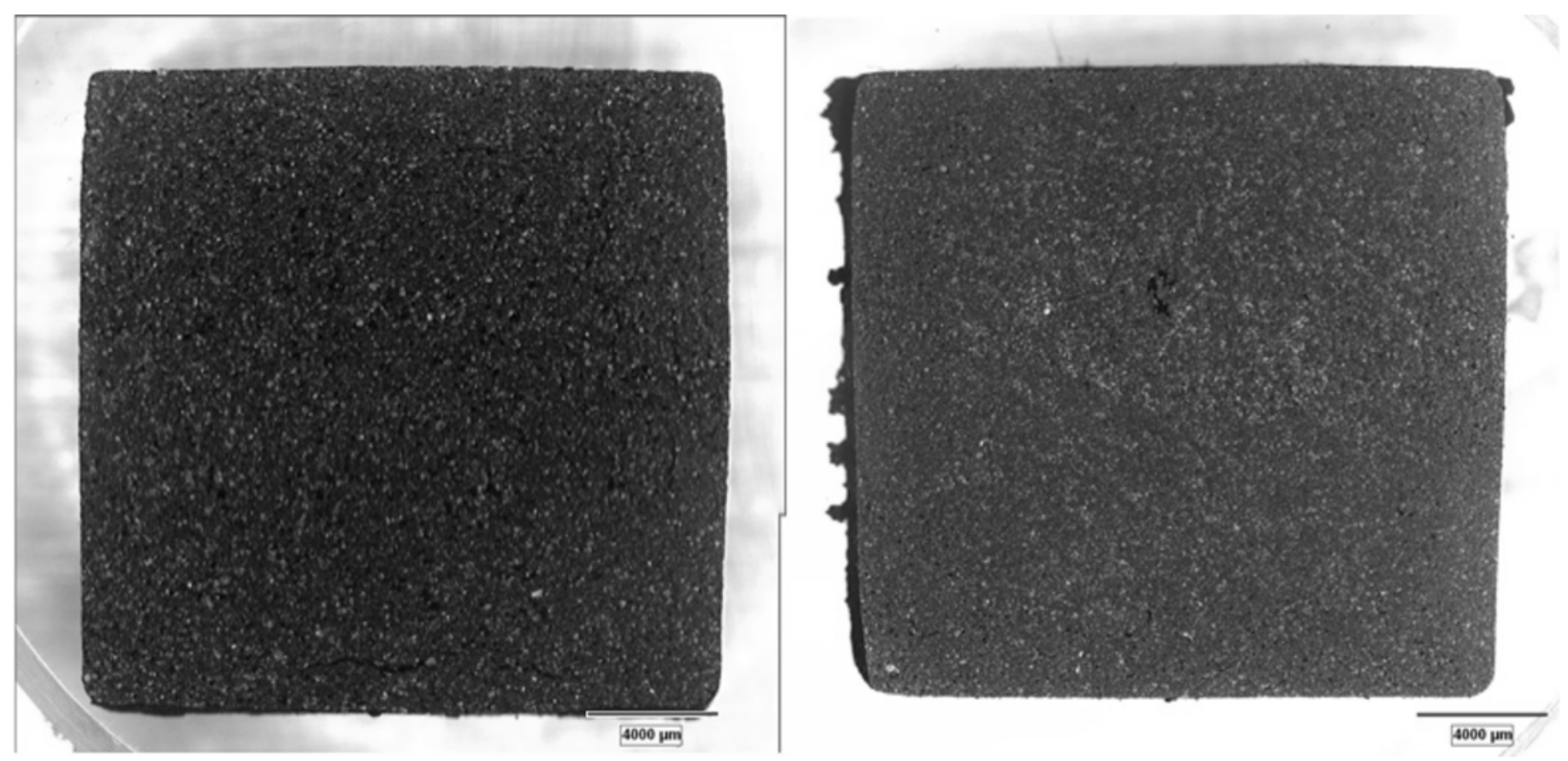

Figure 5. Optical microscopy (5.8x) image of a cross section of a graphite extrusion with the wood flour (left) and epoxy (right) compositions.

SEM images of the baseline material showed agglomeration of the $\mathrm{UO}_{2}$ particles as seen in Figure 6. In order to minimize the agglomeration, $\mathrm{UO}_{2}$ was ball milled for 12 hours prior to blending with the powders. Extrusions made with the milled $\mathrm{UO}_{2}$ qualitatively showed fewer agglomerates. Co-milling of the baseline composition of dry powders for 12 hours also improved the dispersion but was less effective. 


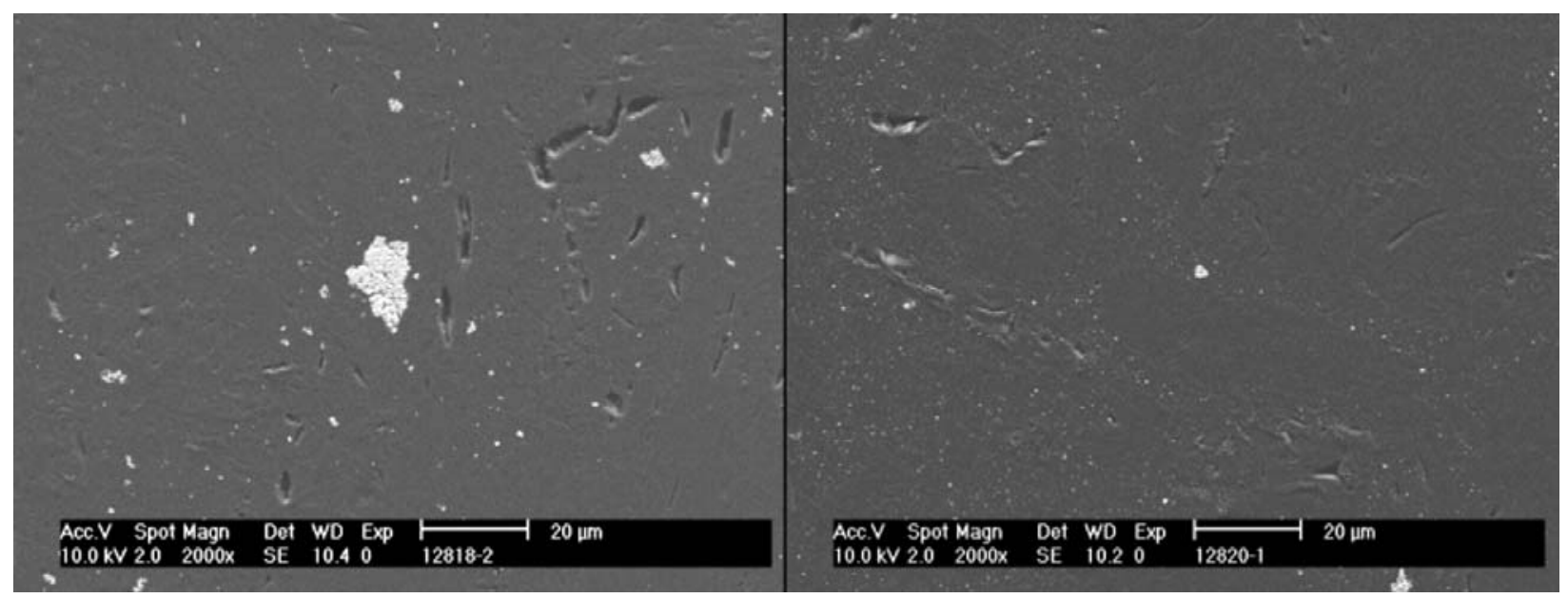

Figure 6: SEM image of extrusion made from the baseline composition with as-received $\mathrm{UO}_{2}$ (left) and milled $\mathrm{UO}_{2}$ (right).

Small pieces of extruded samples were measured by immersion density to measure total volume. Using the slowest heat treatment cycle, the baseline composition started with a density of $1.60 \mathrm{~g} / \mathrm{cc}$ after the $250^{\circ} \mathrm{C}$ heat treatment. This increased to $1.71 \mathrm{~g} / \mathrm{cc}$ with heat treatment to $1250^{\circ} \mathrm{C}$. The immersion density of the epoxy based sample after the first $250^{\circ} \mathrm{C}$ heat treatment was initially acceptable at $1.69 \mathrm{~g} / \mathrm{cc}$; however, the density dropped to an unacceptable $1.26 \mathrm{~g} / \mathrm{cc}$ after heat treating to $1250^{\circ} \mathrm{C}$. Densities excluding open porosity were much higher at $1.78 \mathrm{~g} / \mathrm{cc}$ for the baseline composition and $2.14 \mathrm{~g} / \mathrm{cc}$ for the epoxy composition.

Two samples of an extrusion made from co-milled powders with the baseline composition were prepared for measuring thermal diffusivity using laser flash analysis (LFA). One sample was made parallel to the extrusion direction and the other was made perpendicular to the extrusion direction. The samples were 10 $\mathrm{mm} \times 10 \mathrm{~mm} \times 5 \mathrm{~mm}$ thick. The top and bottom surfaces were ground to be parallel within 20 microns. The samples were measured at room temperature using a Netszch LFA 427. The sample prepared parallel to the extrusion direction had a diffusivity of $34 \pm 0.5 \mathrm{~mm}^{2} / \mathrm{s}$ while the perpendicular sample had a diffusivity of $71 \pm 2 \mathrm{~mm}^{2} / \mathrm{s}$. This can be compared with POCO graphite standards that have a range of diffusivities from 75 to $80 \mathrm{~mm}^{2} / \mathrm{s}$. Although the morphology of cracks in these particular samples is not known, it is likely that there is a preferred crack orientation that resulted in the factor of two difference in diffusivity between the samples. Suggesting that the cracks tend to run parallel with the extrusion direction and; therefore, interfering more significantly with diffusivity.

\section{CONCLUSIONS}

This fabrication feasibility study was initiated to explore options to construct a new LEU core for the TREAT reactor. Fabrication processes similar to those used for the original core were identified and followed. One inch diameter graphite matrix fuel blocks were fabricated by a uniaxial pressing method that closely followed the historical method used to fabricate the original core. This study found that acceptable densities and microstructures could be achieved with this process. Additional characterization of the pressed pellets was not pursued. Extrusion methods similar to those used to produce the "upgrade" TREAT fuel elements were followed to produce samples for characterization. In order to address potential concerns regarding neutronics performance, the graphite content of extrusions was increased from $59 \%$ to $72 \%$ without adverse affects on the microstructure. The major challenge encountered while using this method was the formation of cracks due to volatilization of gases during the low temperature resin cure. Changes to the heat treatment cycle time minimized but did not eliminate cracking. Replacing the historic Varcum type binder with an epoxy binder eliminated the cracking problem but the final density of the sample was significantly decreased. 


\section{ACKNOWLEDGEMENTS}

This work has been performed under the auspices of and supported by the US Department of Energy, National Nuclear Security Administration, Office of Global Threat Reduction.

\section{REFERENCES}

1 J.H. Handwerk, R.C. Lied, "The Manufacture of the Graphite-Urania Fuel Matrix for TREAT", ANL5963, 1960.

2 K.V. Davidson, D.H. Schell, “TREAT Upgrade Fuel Fabrication, LANL, LA-UR-79-821, CONF790625-2.

3 L. Lyon, "Performance of (U,Zr)C-Graphite (Composite) and of (U,Zr)C Carbide Fuel Elements in the Nuclear Furnace 1 Test Reactor", LA-5398-MS, 1973.

4 E. Luther, C. Chen, D. Dombrowski, J. Kennison, P. Papin, D. Guidry, J. Hunter "Fuel Fabrication Study for TREAT Conversion Fuel”, LA-UR-13-27850, 2013.

5 E. Luther, R. Leckie, D. Dombrowski, P. Papin "Update on Fabrication of Extrusions for TREAT Trade Study", Report LA-UR-14-21458, 2014.

6 R. Swanson and L. Harrison, "The Effect of Carbon Crystal Structure on TREAT Reactor Physics Calculations", CONF-880911-23, 1988 International Reactor Physics Conference, Jackson Hole, WY. 7 K.V. Davidson, W.W. Martin, D.H. Schell, J.M. Taub, J.W. Taylor, "Development of Carbide-Carbon Composite Fuel Elements for Rover Reactors (U)", AEC Research and Development Report, LA-5005, 1972.

8 E. Luther, D. Dombrowski, J. Kennison, P. Papin, D. Guidry, "Material Compatibility Study for TREAT Conversion Fuel", LA-UR-13-26469, 2013. 